\title{
Polymers as Building Envelope Materials
}

\author{
Mohamed, Elgarhy.
}

\begin{abstract}
The building envelope regards as a barrier separating the interior from the exterior environment. Architects create an isolated environment, and engineers equipped it with energy-using devices to control climate conditions, this leads to increase energy consumption rates. Because of the need to conserve energy, the building envelope is seen as a dynamic boundary, which interacts with the external natural energy forces and the internal building environment. Polymers have been used as complementary materials, and when their properties are identified, they can be transformed from complementary materials to essentials. Thus, a comparative analysis method is used for identifying the different applications of polymers used in the design and implementation of the building envelope components, knowing their advantages over other materials, indicating their impact on reducing the energy consumption rates inside interior spaces, and showing their ability to create new envelopes.
\end{abstract}

Keywords - Building envelope, Dynamic boundary, Polymers, Application

\section{INTRODUCTION}

$\mathrm{P}$ OLYMERS have a wide range of applications in building industry, and this sector is the second largest user of polymers. These applications range from non-structural to structural uses, inside and outside of the building, because of polymers have several advantages such as they are light, durable, and economical, have high performance characteristics, are easily handled and processed, and offer different options such as colors, surface qualities and aesthetic properties [1].

This paper shows applications where polymers from either part or the whole of the building envelope, It characterizes the architectural expression of a building, separate indoors from outdoors and provides protection against the weather while simultaneously allowing light to pass through, also aims to know their impact in creating new designs for the buildings envelopes such as singly, doubly curved shells, hyperbolic paraboloid, conic forms, pneumatic structures, dynamic envelopes and digital forms.

Mohamed Adel Abdullah. Elgarhy is postgraduate student, Department of Architecture, Faculty of Engineering, Alexandria University, Egypt and Demonstrator, Department of Architecture, Higher Institute for Engineering and Technology, Kafr El sheikh Governorate, Egypt. (Corresponding author to provide phone: 002-01063437971; fax: 002-0473211865; email:www.arch.elgarhy@gmail.com)

\section{II.THE APPLICATION OF POLYMERS IN THE BUILDING ENVELOPE}

Nowadays polymers have become an increasingly important part of the general group of engineering materials. Their range of interesting properties and applications are at least as broad as that of other major groups of materials, and ease of fabrication frequently makes it possible to produce finished items economically. Important industries such as fibers, rubbers, adhesives, sealants, coatings and caulking compounds are based on polymers.

\section{A. Insulation Applications of Polymers in the Building Envelope}

In general, insulation applications of polymers in construction can be one of the following three types: heat insulation, moisture insulation, and sound insulation.

\section{Heat Insulation}

Heat insulation materials shown in Fig. 1 are used to reduce the heat transfer through the building envelope. There are five different types of heat insulation [2]

- Loose fill insulation consists of mineral wool fibers, granular vermiculite, and treated cellulose fibers. It is poured by hand or blown through a nozzle into a cavity.

- Foamed in place insulation is made of foamed polyurethane. By filling all corners, cracks, and crevices for an airtight seal, foamed insulation eliminates random air leakage, which can account for up to 40 percent of heating energy.

- Insulation batts and blankets are solid in bundles or rolls. Because fiberglass batts are inexpensive, they are the most common type of residential insulation.

- Rigid insulation comes in blocks, boards, and sheets and is performed for use on pipes. It is made of Polyurethane foam and extruded-expanded Polystyrene polymers.

- Reflective insulation uses material of high reflectivity and low emissivity, such as paper-backed aluminum foil or foil-backed gypsum board, and foil-faced Polyethylene bubbles in conjunction with a dead-air space to reduce the transfer of radiant heat.

Rigid foam structures of extruded polystyrene (usually colored), EPS (usually white colored), and PU in the form of panels, boards, and sandwich panels are widely used in insulation, for exterior and interior for energy conservation purposes. Polyurethane foams have the highest R (thermal 
transfer resistance) value of any insulation as shown in Fig. 2 although; they are not very cost effective [3].

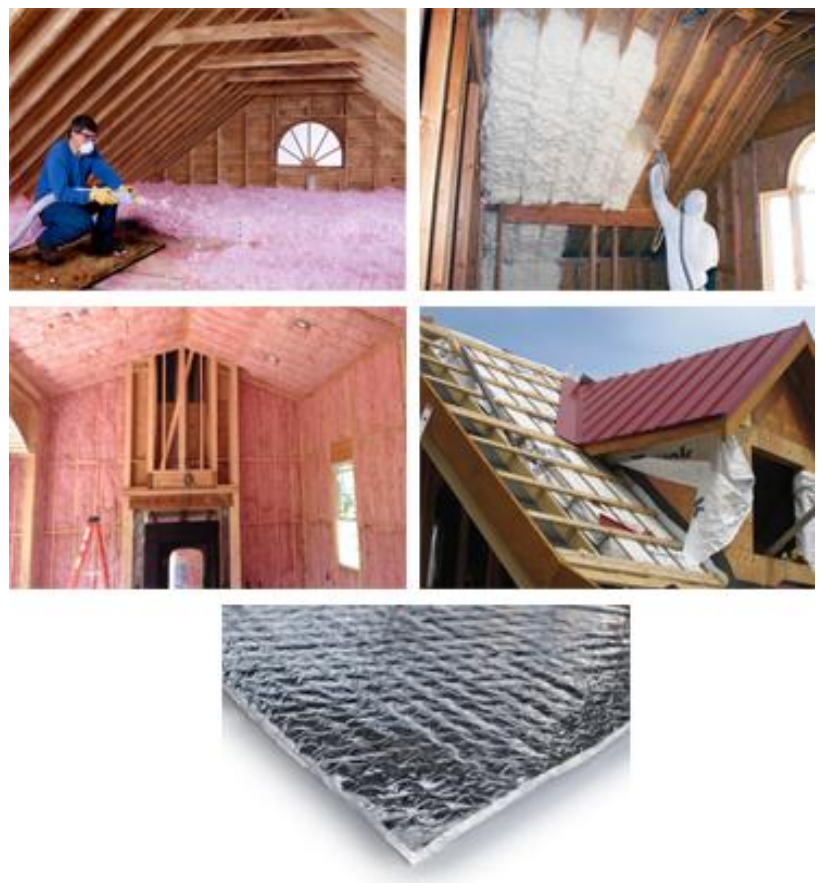

Fig.1 represents the different types of heat insulation [4].

One study shows that more than $60 \%$ of all domestic energy consumption is for space heating, and that improvement in thermal insulation, results in at least a $35 \%$ saving [1]. When polymers insulation materials compared to mineral wool and glass foam, the result showed that on average polymers insulation materials consume $16 \%$ less energy and produce 9 $\%$ less greenhouse gases emissions than the alternative mix of mineral wool and glass foam in total life-cycle [5].

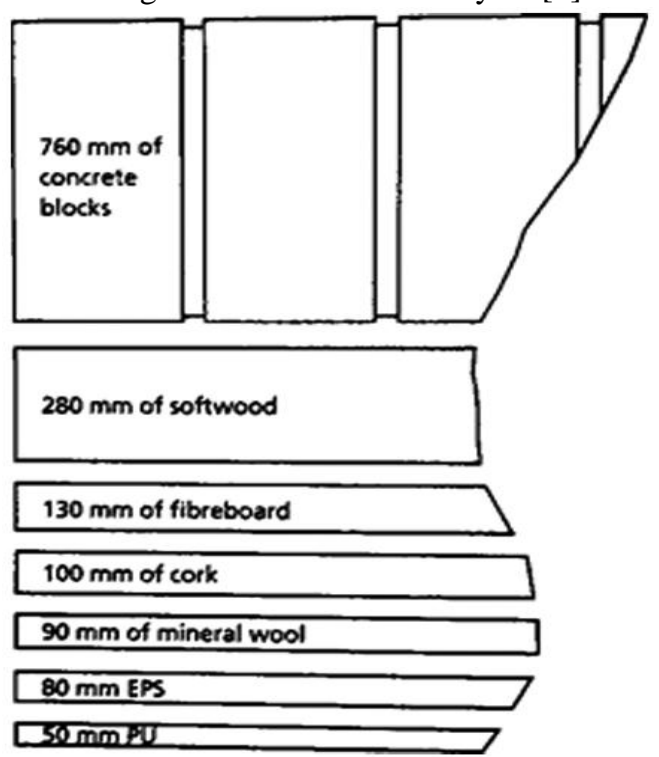

Fig. 2 shows heat insulation characteristics of different insulation materials with their average thickness to provide the same level of insulation [1].

\section{Moisture Insulation}

In the past, paper or asphalt were used as a moisture vapour barrier for the building envelope. Today many polymers such as polyolefin (polyethylene, polypropylene), polyvinylchloride, polymides, polyethlene tetraphthalate, polycarbonate, and others are used as protective barrier films against the mass transport of small molecules of vapours, gases and liquids. The barrier properties depend on the polymer characteristics such as diffussion, permeability, the nature of fluid, and temperature [4].

\section{Sound Insulation}

The required degree of sound insulation may be provided by utilizing a composite design. In sandwich construction this can be achieved by a filled foam core or by a plaster board as a lining material, which reduce levels of airborne sound from plumbing, outside noises, or indoor activities such as home theaters [6].Fig. 3 shows noise reduction coefficient (NRC) for selected materials. It measures how well materials stop sound from reflecting (how much sound they can absorb).

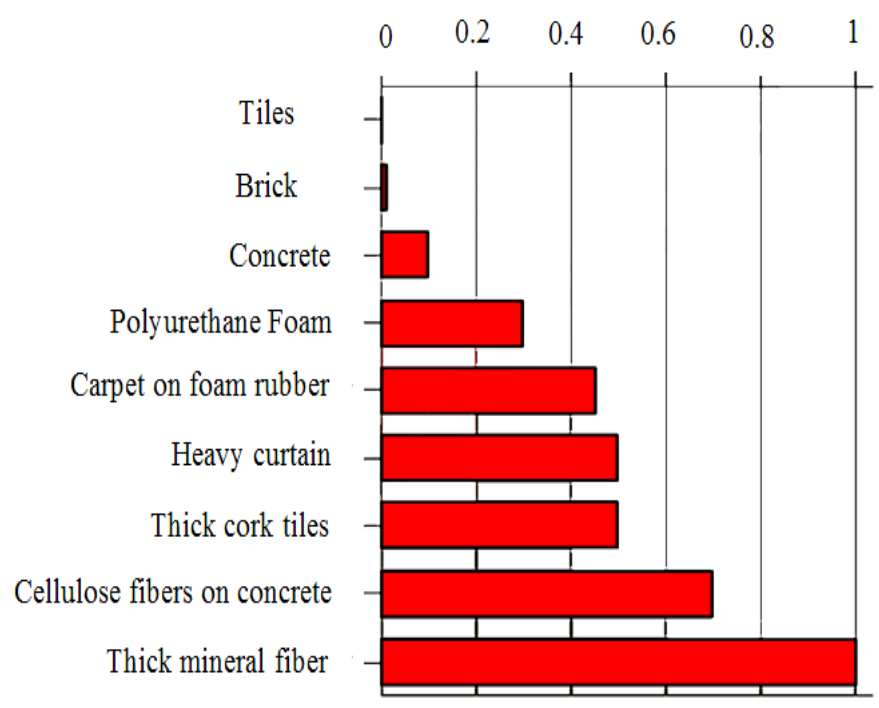

Fig.3 noise reduction coefficient for Polyurethane is better than carpet, thick cork tiles, and heavy curtain [7].

\section{B. Structural Applications of Polymers in the Building Envelope}

Structural applications are require proper mechanical performance like strength and stiffness in the material, which may or may not bear the load in the structure. They include sandwich panels, cladding, glazing, profiles, coated fabrics, and others.

\section{Sandwich Panels}

Sandwich panels as shown in Fig.4 are layered structures with thin; two high modulus (metallic, concrete or polymeric) facing adhered to a lightweight core of foam or honeycomb as shown in table I. Standard panel thickness is $5 \mathrm{~cm}$ with thickness up to $12.7 \mathrm{~cm}$. 
RELATIVE STIFFNESS, STRENGTH AND WEIGHT OF HONEYCOMB SANDWICH PANEL VS SOLID SHEET [8].

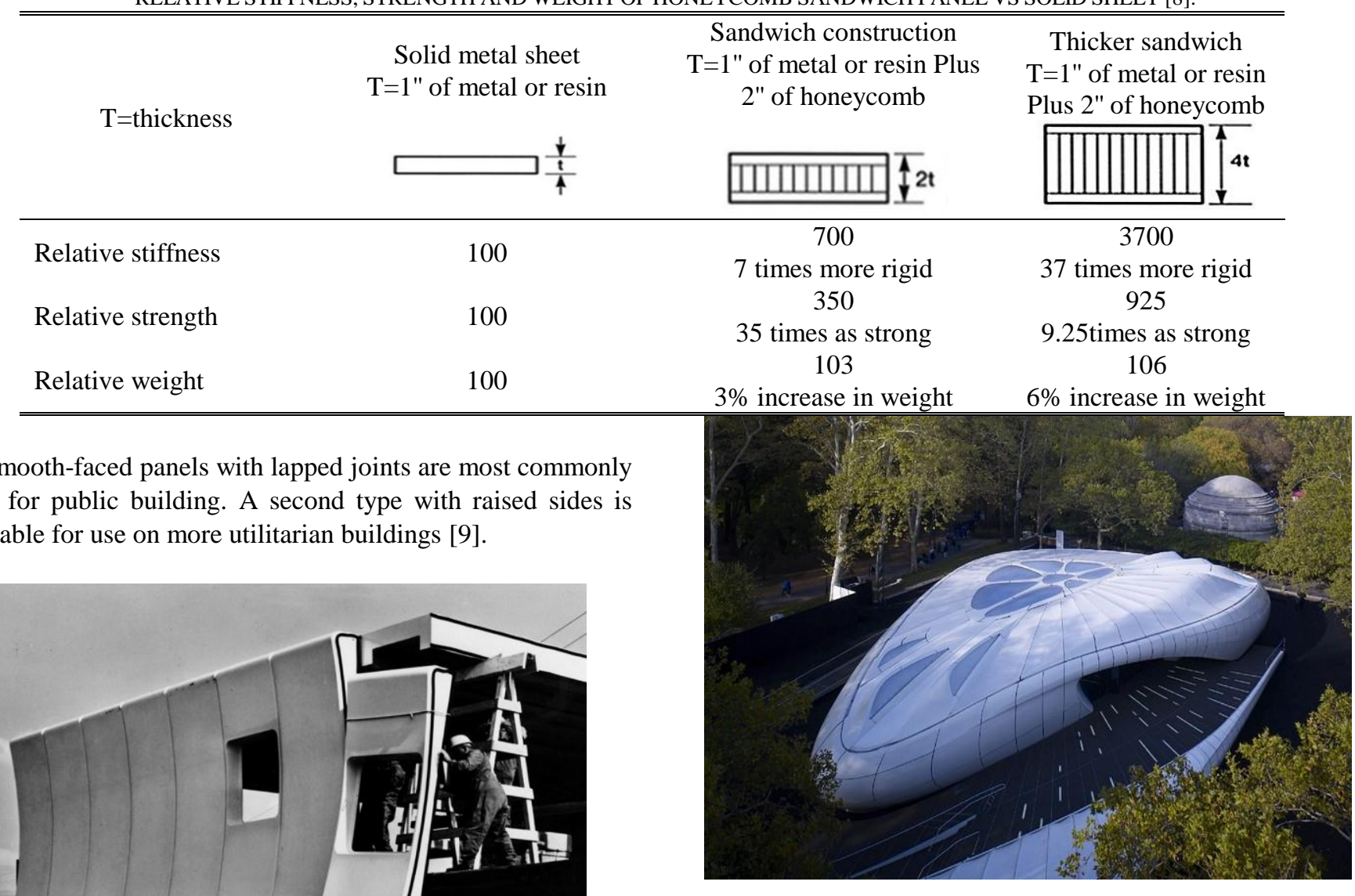

Fig.5 GRP (glass fiber reinforced polyester) was chosen as an ideal cladding material for Chanel mobile art pavilion in central park, New York [10].

Table II shows summary ratings for some claddings materials according to BREEAM (Building Research Establishment Environmental Assessment).

TABLE II

GLASS FIBER REINFORCED CONCRETE AND GLASS FIBER REINFORCED POLYESTER IS BETTER THAN PRECAST CONCRETE CLADDING [12].

Fig.4 shows the FG (fiber glass) 2000 project in Germany; the individual elements are sandwich elements with 4-6 mm thick GRP layers either side of a $60 \mathrm{~mm}$ thick rigid Polyurethane foam core [10].

\section{Claddings}

Currently, PVC (Polyvinylchloride) siding has about 50\% of the market share for exterior cladding products on residential and commercial buildings. The popularity of use of PVC in cladding is because of the durability, ease of maintenance, versatility and low installation cost [1].

Larger claddings are usually prepared from polyester based glass fiber reinforced polyester as shown in Fig.5. There is also a trend for the use of cladding panels made of phenolic as their excellent flame resistances are considered, in particular for airport terminals, hospitals, and schools [11]. 
building mass as shown in Fig. 10. Twin-layer membranes can also make these more environmentally efficient, and a wide interior ambiences [13]. range of opacity and surface treatments can create various

TABLE III

COMPARISON BETWEEN EXTERNAL USE FABRICS IN DIFFERENT PROPERTIES [14]

\begin{tabular}{|c|c|c|c|}
\hline Properties & PVC coated polyester & PTFE coated glass fiber & Silicon coated glass fiber \\
\hline Life expectancy & •...... & .......... & •....... \\
\hline Strength & $\bullet \bullet \bullet \bullet \bullet$ & $\bullet \bullet \bullet \bullet \bullet \bullet$ & $\bullet \bullet \bullet \bullet \bullet \bullet$ \\
\hline Maintenance & ..... & •......• & .... \\
\hline Translucency & ..... & •.•• & ..... \\
\hline Flame resistance & ..... & ......... & ......... \\
\hline Printable & ........ & - & - \\
\hline
\end{tabular}

\section{Claddings}

Polycarbonate as shown in Fig. 6 and acrylic are more breakage resistant than glass, which makes its suitable for skylights and windows glazing in different areas such as correctional facilities and schools. They are bendable, have better sound-loss characteristics than glass, and can be laminated to provide lightweight bullet-resistant lite [15].

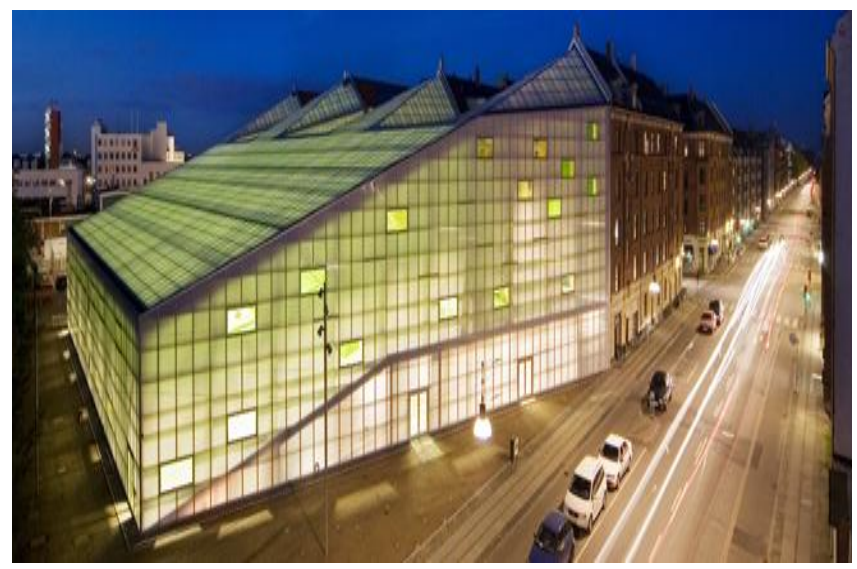

Fig.6 Polycarbonate used as a glazing material in Sports and culture center in Holmbladsgade, Copenhagen [16].

Architects unfamiliar with these products can read manufactures product literature to acquaint them with the detailing required to frame and seal the edges as well as the code limitations and the advantages they offer over conventional glazing such as [17].

- Polymers can be bent to curves far more easily than glass. They are the materials of choice in curved skylights such as domes.

- Polymers glazing are lighter than glass.

- Polymers are several times stronger than glass of the same thickness and are also more impact resistant. It does not shatter or crack like glass, therefore, they are specified in fenestration where glass breakage due to vandalism is a concern or where a high degree of security is required.

\section{Profiles}

Windows frames made of PVC represent a large group within range of polymers profiles where there low thermal conductivity can be turned to an advantage in heat savings. PVC windows or PVC door profiles are manufactured as hollow-section profiles and welded to form the finished product as shown in Fig.7 [18].

There are several advantages for using polymers in windows frames over other materials such as [1].

- Their lower thermal conductivities compared to equivalent metal frames, which provides more effective thermal insulation helping to reduce condensation on the frame.

- They can be more easily assembled.

- They don't require regular maintenance, and don't need a wooden surround a sub-frame.

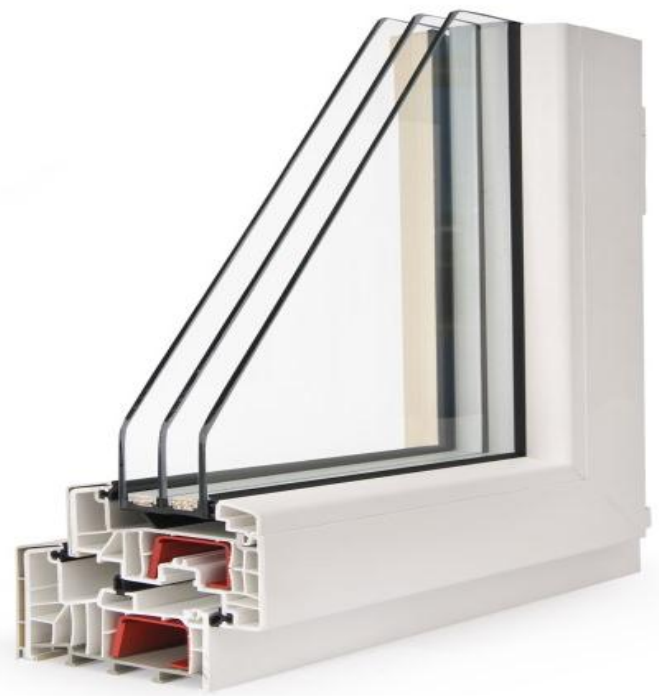

Fig.7 PVC frames and sashes are almost maintenance free because vinyl does not corrode or degrade due to fungal or termite attack [10].

\section{POLYMERS ABILITY TO CREATE NEW BUILDING ENVELOPES}

As polymers were invented in the 19th century and went into large scale production in the early 20th, it seemed as through this vision had become reality. Architects lincked their hopes and dreams to polymers, which apparently could be given all conceivable characteristics. It combined lightness, strength, transparency, thermal insulation capacity, and opened up a world of infinite shapes [19]. 


\section{A. Shell Structures}

Shell structures may be divided broadly into singly curved shells and doubly curved shells, which classified to Synclastic and Anticlastic shells as shown in Fig. 8 [20].

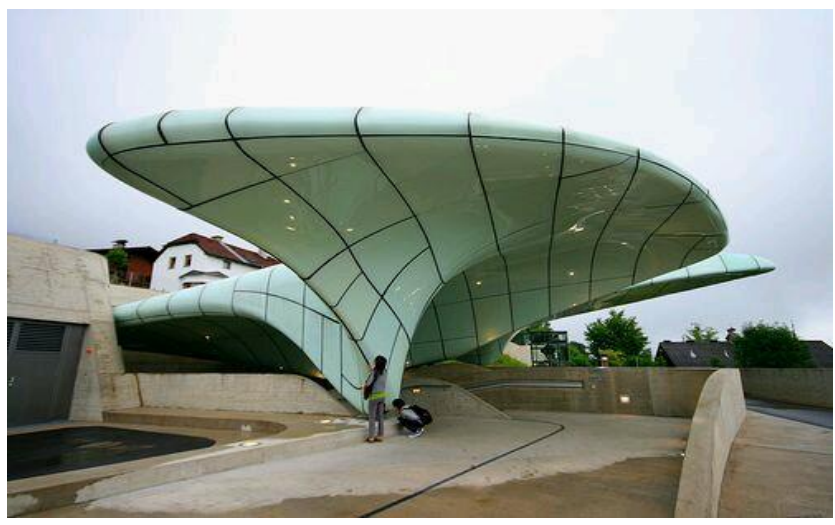

Fig.8 Glass fiber reinforced polyester was used to clad Nordpark railway station entrance [21].

\section{B. Membrane Tension Structures}

The apparently weightless forms made from transparent sheets and synthetic fabrics are the result of modern, engineered membrane construction. Again and again, trials were conducted in an attempt to replace conventional tent materials by modern fabrics such as PVC coated polyester and PTFE coated glass fiber, because of the advantages promised by the new materials were already evident [19].

\section{Hyperbolic Paraboloid}

Any point on the membrane surface can be restrained by the corner points.

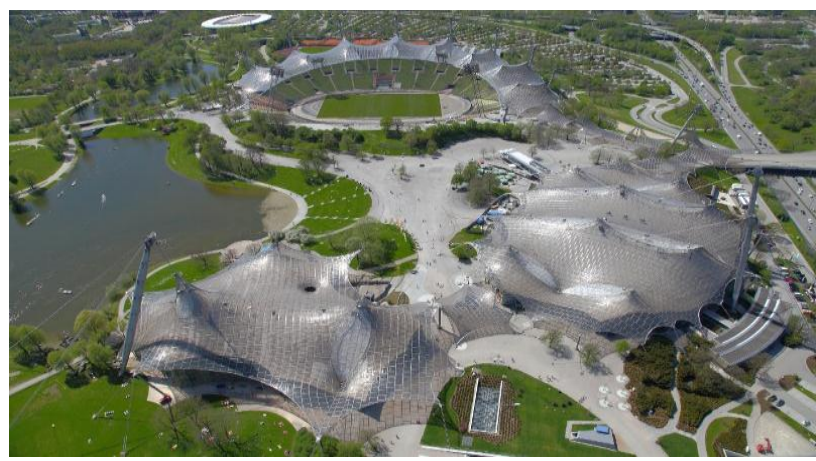

Fig.9 Acrylic panels clad the tensile membrane in Munich Olympic stadium [20].

The high points pick up any downloads and the low points resist the wind uplift as shown in Munich Olympic stadium Fig.9, which the canopies membrane is suspended from a multitude of vertical masts that allow for the dramatic draping curves of the surface to flow dynamically across the site changing form, scale, and sectional characteristics [22].

\section{Conic Form}

The creative challenge to architects is to explore the development of striking new forms, which satisfy the structural requirements of the membrane surface. Developing new shapes of push-up elements, and varying the design of the perimeter connections enables dramatic variation in the appearance of a structure as shown in Fig. 10 [23]

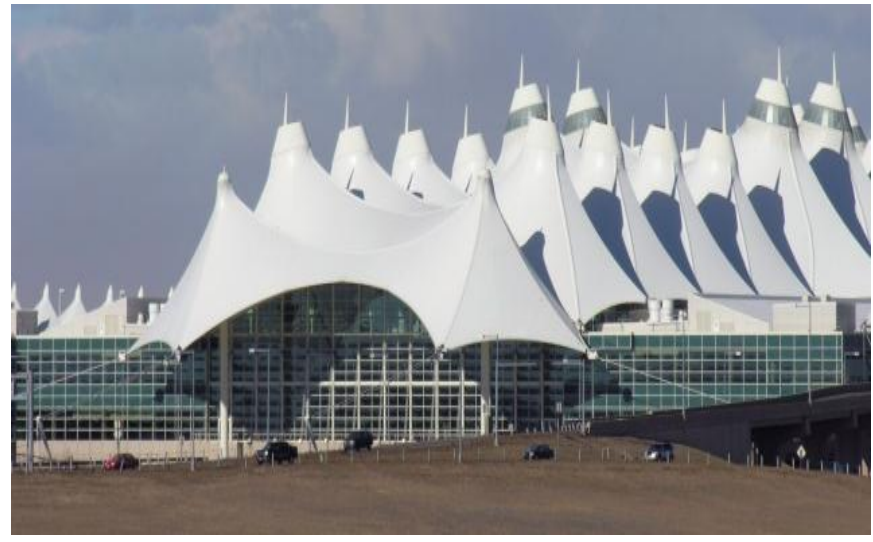

Fig.10 The roof of Denver International Airport consists of a series of PTFE tent-like modules [24].

\section{Pneumatic Structures}

Pneumatic structures are flexible membrances that derive their stability from air pressure. Recently, developed materials such as polytetrafluoroethylene (PTFE or Teflon) and ethylenetetrafluoroethylene (ETFE) are light, strong, durable, and suitable for Pneumatic Constructions. Air supported and air inflated considers the main types of pneumatic structure as shown in fig.11 [25].

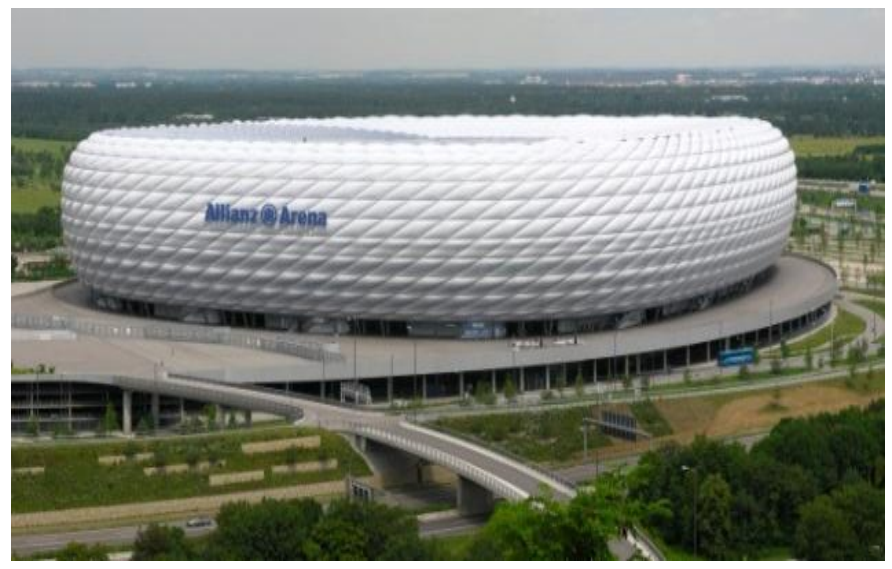

Figure 11: Allianz-Arena Stadium in Germany looks like a monolithic air - filled ETFE cushions floating above the ground [21].

\section{Dynamic Forms}

Kas Oosterhuis has developed a concept using the fluidic muscle as shown in fig.12 to create an adaptive façade, an inflatable sunshade device that is more economic in material and maintenance costs, but also more interactive and dynamic in operation [26]. 


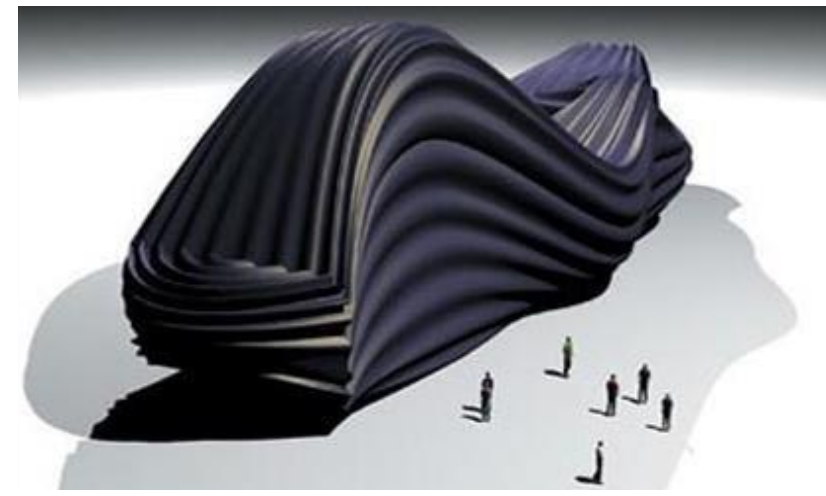

Figure 12: The elongation and contraction for pneumatic strips converts the digital information into motion and changes the form of the pavilion [19].

\section{CONCLUSIONS AND RECOMMENDATIONS}

Increased levels of heat, moisture and sound insulation in the building envelope components are a cost-effective way of reducing energy consumption rates. In several domestic and other small buildings, it has already been demonstrated that the additional costs of insulation can be offset against a much reduced cost for the heating system involving a whole building radiator and central boiler option.

The variety of polymers applications in the building envelope is almost never-ending, and every day there are several new ones appearing as structural or non-structural applications. Sandwich panels, cladding, glazing, profiles, coated fabrics, coatings, sealants, adhesives and composites consider from these applications, which have many advantages over the same applications made from another materials.

The different applications of polymers help architects to create untraditional forms for the buildings envelopes such as singly, doubly curved shells, parallel vaults, conic forms, pneumatic structures, dynamic envelopes, and digital forms.

It's recommended to exploit light structures of polymers, which can be moved, disassembled, installed, and don't need to energies or huge investments in some fields such as emergency shelters after wars, earthquakes and development fields in deserts, which includes lands reclamation, mining, and tourism development.

\section{REFERENCES}

[1] A. Guneri, Polymers in Construction. United Kingdom: Rapra Technology Limited, 2005, pp. 3-7- 45- 46 -50.

[2] B. Corky, Building Systems for Interior Designers. New Jersey: John Wiley \& Sons, Inc., 2003, pp.97.

[3] B. Linda, Designing the Exterior Wall, an Architectural Guide to the Vertical Envelope. USA: John Wiley \& Sons, Inc., 2005, pp.67.

[4] B. Varis, The Whole Building Handbook, How to Design Healthy, Efficient and Sustainable Buildings. London: Earth scan, 2010, pp. 39$42-60$.

[5] H. Pilz, B. Brandt, R. Fehringer, The Impact of Plastics on Life Cycle Energy Consumption and Greenhouse Gas Emissions in Europe. Vienna: Plastics Europe, Association of Plastics Manufacturers, 2010, pp.14.

[6] M. Charles, P. Shenoy, Selecting Thermoplastics for Engineering Applications. New York: Marcel Dekker, Inc., 1997, pp.71.

[7] http://www.explainthatstuff.com, accessed 22-3-2017.
[8] http://www.panelite.uk, accessed 23-3-2017.

[9] C. William, Materials Science and Engineering, An Introduction. New York: John Wiley \& Sons Ltd., 2007, pp. 611.

[10] E. Stephan, Plastics in Architecture and Construction. Basel: Birkhauser, 2010, pp. 79-97-151.

[11] B. Alan, Cladding of Buildings. New York: Taylor \& Francis e-Library, 2002, pp. 49.

[12] http:// www.bre.co.uk, accessed 25-3-2017.

[13] D. Jiri, Technology of Fluor polymers. Boca Raton: CRC Press, Taylor \& Francis Group, 2009, pp. 142.

[14] http://www.architen landrell.com, accessed 28-3-2017.

[15] N. Fred, Time-Saver Details for Exterior Wall Design. New York: McGraw-Hill, 1996, pp. 103.

[16] B. Verlagshaus, Pure Plastic, New Materials for Today's Architecture. Frankfurt: Deutsche Bibliothek, 2008, pp.73.

[17] M. Madan, Building Construction:Principle, Mateials, and Systems. Boston: Pearson Education, Inc., 2013, pp.741.

[18] P. Varghese, Building Construction. New Delhi :PHI Learning Private limited, 2012, pp. 235.

[19] J.Simone, Transparent Plastics, Design and Technology. Basel: Birkhauser, 2008, pp. 17-30-34.

[20] M. Angus, Structural Design for Architecture. Oxford: Architectural Press, 1997, pp. 11-90.

[21] W. Andrew, Modern Construction Handbook. New York: Springer, 2009, pp.35-58.

[22] B. Leonard, Integrated Buildings, The Systems Basis of Architecture. New Jersey: John Wiley \& Sons, Inc., 2003, pp. 258.

[23] C. Andrew, structure as architecture, a source book for architects and structural engineers. New York: Routledge, 2015, pp.20.

[24] S. James, Ecological Architecture. London: Thames\& Hudson Ltd, 2005, pp.90.

[25] D. Andrea, Constructing Architecture, Materials-Processes-structures. Berlin: Birkhauser, 2008, pp.164.

[26] C. Helen, "Fabric Architecture and Flexible Design," Architectural Design, vol. 76, no 6, pp. 79, November 2006. 